\title{
Caloric Restriction Reverses Hepatic Insulin Resistance in Aging Rats by Decreasing Visceral Fat
}

\author{
Nir Barzilai, Swati Banerjee, ${ }^{\star}$ Meredith Hawkins, Wei Chen, and Luciano Rossetti \\ Department of Medicine, Division of Geriatrics, Division of Endocrinology, and *Division of Pediatric Endocrinology, and the Diabetes \\ Research and Training Center, Albert Einstein College of Medicine, New York 10461
}

\begin{abstract}
Hyperinsulinemia and increased visceral/abdominal fat (VF) are common features of human aging. To examine the relationships among VF, peripheral, and hepatic insulin sensitivity, we studied 4- and 18-mo-old male Sprague-Dawley rats $(n=42)$ fed ad libitum (4 AL and $18 \mathrm{AL})$ or moderately calorie restricted $(18 \mathrm{CR})$ up to $18 \mathrm{mo}$ of age. Total fat mass (FM) and VF were decreased in $18 \mathrm{CR}$ to approximately one-third of that of $18 \mathrm{AL}(P<0.001)$, while lean body mass (LBM) was unchanged. Most important, $18 \mathrm{CR}$ had more FM (65 \pm 6 vs. $45 \pm 6 \mathrm{~g})$ but less VF $(7.8 \pm 0.6$ vs. $12.3 \pm 3.3 \mathrm{~g})$ compared with 4 AL $(P<0.01$ for both). Thus, the effects of variable VF on HIS could be assessed, independent of FM and age.

Marked hepatic insulin resistance ensued with aging (18 $\mathrm{AL}$ ) and CR restored hepatic insulin sensitivity to the levels of young rats, while peripheral insulin sensitivity remained unchanged (by insulin clamp of $18 \mathrm{mU} / \mathrm{kg} / \mathrm{min}$ ). In fact, the rates of insulin infusion required to maintain basal hepatic glucose production in the presence of pancreatic clamp were $0.75 \pm 0.10,1.41 \pm 0.13$, and $0.51 \pm 0.12 \mathrm{mU} / \mathrm{kg} \cdot \mathrm{min}$, in $4 \mathrm{AL}, 18 \mathrm{AL}$, and $18 \mathrm{CR}$, respectively $(P<0.01$ between all groups), and in $18 \mathrm{CR}$ rats infused with insulin at similar rates as in the $18 \mathrm{AL}(1.4 \mathrm{mU} / \mathrm{kg} / \mathrm{min})$ hepatic glucose production was decreased by $32 \%(P<0.005)$. Furthermore, when $18 \mathrm{CR}$ rats were fed AL for $14 \mathrm{~d}$, VF rapidly and selectively increased and severe hepatic insulin resistance was induced. We propose that in this animal model the ageassociated decrease in hepatic (rather than peripheral) insulin action is the major determinant of fasting hyperinsulinemia and that increased visceral adiposity plays the major role in inducing hepatic insulin resistance. Thus, interventions designed to prevent the accumulation of VF are likely to represent an effective mean to improve carbohydrate metabolism in aging. (J. Clin. Invest. 1998. 101:1353-1361.) Key words: visceral fat • hepatic insulin resistance - aging • hepatic glucose flux $\bullet$ caloric restriction
\end{abstract}

Address correspondence to Nir Barzilai, M.D., Divisions of Geriatrics and Endocrinology, Dept. of Medicine, Belfer Bld. \#701, Albert Einstein College of Medicine, 1300 Morris Park Avenue, Bronx, NY 10461. Phone: 718-430-3312; FAX: 718-430-8557; E-mail: barzilai@ aecom.yu.edu

Received for publication 24 April 1997 and accepted in revised form 20 January 1998.

J. Clin. Invest.

(C) The American Society for Clinical Investigation, Inc. 0021-9738/98/04/1353/09 \$2.00

Volume 101, Number 7, April 1998, 1353-1361

http://www.jci.org

\section{Introduction}

Aging in both humans and rodents is associated with increased fasting and postprandial plasma insulin levels, suggesting an insulin-resistant state (1-3). However, though increased body weight $(\mathrm{BW})^{1}$ and fat mass $(\mathrm{FM})$ are commonly associated with insulin resistance in aging (4-7), the relationship between aging and insulin resistance is confounded by associated factors such as decreased physical activity, dyslipidemia, hypertension, non-insulin-dependent diabetes mellitus, and coronary heart disease (4). Furthermore, visceral/abdominal fat (VF) increases in older men and women, independent of body mass index (8-10). Most important, increased VF has been associated with a decrease in insulin sensitivity as measured by hyperinsulinemic clamp (11) and leg balance studies (12), and VF accounted for the majority of the variability in insulin sensitivity in other heterogeneous populations of women (13) and men (14). Thus, the effects of VF on insulin action may be independent of body mass index and are a typical feature of aging.

Although the anatomical location of VF would support its role in regulating hepatic insulin action and carbohydrate metabolism, surprisingly there are virtually no studies designed to address this important issue. It has been hypothesized that "portal" effects of FFA and glycerol released by the increased mesenteric fat tissue may cause hepatic insulin resistance (15, 16), supporting a major role for increased VF in regulating hepatic glucose metabolism. In humans, rates of basal hepatic glucose production (HGP) were reported to be normal with aging (17-19); however, suppression of HGP by an oral glucose load $(20)$ or by insulin $(20,21)$ was significantly impaired with aging, and in younger subjects with increased abdominal obesity (22). In addition, simply measuring the rate of HGP in human aging fails to take into account the fact that peripheral and portal insulin levels are markedly increased. Thus, the increase in VF may be responsible for the resistance of the aging liver to the suppressive effect of insulin.

Recently we have delineated the changes in body composition and glucose metabolism in animal models of aging (23, 24). Animal models have the advantage of allowing one to investigate potential mechanisms by which aging and caloric restriction (CR) affect carbohydrate homeostasis in the absence of other confounding genetic and/or metabolic conditions which are associated with the syndrome of insulin resistance (4). In this rodent model, peripheral insulin responsiveness is

1. Abbreviations used in this paper: $\mathrm{AL}$, ad libitum fed; $\mathrm{BW}$, body weight; CR, caloric restriction; FM, fat mass; GC, glucose cycling; Glc-6-P, glucose-6-phosphate; Glc-6-Pase, glucose-6-phosphatase; HGP, hepatic glucose production; HIS, hepatic insulin sensitivity; IIR, insulin infusion rate; LBM, lean body mass; TGO, total glucose output; VF, visceral fat. 
not decreased with fat accretion after late adulthood (24), supporting the notion that a decline in hepatic insulin sensitivity (HIS) accounts for the age-dependent increase in plasma insulin concentrations. Indeed, we reported that the ability of insulin to inhibit HGP was markedly impaired with aging in this rodent model (24). Additionally, since HIS was inversely related to the increases in FM, VF, and FFA levels (24), we suggested that age-related changes in body composition, and their biochemical consequences, may directly lead to the impairment of hepatic glucose metabolism.

To provide further evidence in support of a cause-effect relationship between VF and hepatic insulin resistance in this animal model of aging, we examined whether the age-dependent decrease in HIS could be reversed by the decrease in VF induced by chronic caloric restriction.

\section{Methods}

\section{Experimental rats}

Male Sprague-Dawley rats (Charles River Laboratories, Wilmington, MA) were used in all studies $(n=42)$. At $\sim 15$ wk of age, rats were assigned to be fed ad libitum (AL, $n=25)$ or to CR $(n=17)$ with $55 \%$ of the calories consumed by AL. This level of CR results in lean healthier rats with increased longevity when compared with their AL obese littermates. The chow contained $64 \%$ carbohydrates, $30 \%$ proteins, and $6 \%$ fats with a physiological fuel value of $3.30 \mathrm{kcal} / \mathrm{g}$ chow, and vitamin supplementation was added to the CR rats. Rats were housed in individual cages and subjected to a standard light (6 a.m. to 6 p.m.)/dark (6 p.m. to 6 a.m.) cycle. Rats were studied at 4 mo of age (4 AL, $n=13$ ) and after they were at least 18 mo of age (18 AL: $n=$ 12, average age was $19 \pm 1 \mathrm{mo}$, and $18 \mathrm{CR}: n=17$, average age was $21 \pm 1 \mathrm{mo}) .1 \mathrm{wk}$ before the in vivo study, rats were anesthetized with an intraperitoneal injection of pentobarbital $(50 \mathrm{mg} / \mathrm{kg} \mathrm{BW})$ and indwelling catheters were inserted in the right internal jugular vein and in the left carotid artery. The venous catheter was extended to the level of the right atrium and the arterial catheter was advanced to the level of the aortic arch (23-26). Recovery was continued until BW was within $3 \%$ of their preoperative weight. A subgroup of $18 \mathrm{CR}$ rats $(n=6)$ was studied after 2 wk of ad libitum feeding, and when BW was increased by at least $5 \%$. Studies were performed in 6 -h fasted, awake, unstressed, chronically catheterized rats (23-26).

\section{Body composition}

Lean body mass (LBM) and FM were calculated from the whole body volume of distribution of water, estimated by tritiated water bolus injection in each experimental rat $(23,24,27)$. Briefly, boluses of $20 \mu \mathrm{Ci}$ of ${ }^{3} \mathrm{H}_{2} \mathrm{O}$ (New England Nuclear, Boston, MA) were injected intraarterially on the morning of the study. Steady state for ${ }^{3} \mathrm{H}_{2} \mathrm{O}$ specific activity in rats is generally achieved within $30-45$ min. Five samples were collected between 1 and $3 \mathrm{~h}$ after injection. The distribution space of water was obtained by dividing the total radioactivity injected by the steady-state specific activity of plasma water which was assumed to be $93 \%$ of the total plasma volume. LBM was calculated from the whole body water distribution space divided by 0.73 , and FM was calculated as BW - LBM. In addition, protein concentrations per gram of rectus muscle and gram of liver were measured in all rats studied, and no age-related changes were demonstrated. Epididymal, mesenteric, and perinephric fat were dissected and weighed at the end of each experiment. In addition, a subgroup of rats were anaesthetized with an intraperitoneal injection of pentobarbital and were placed supine in an MRI machine and studied at $1.5 \mathrm{~T}$. Images were obtained with $0.15 \mathrm{~mm}$ between cuts throughout the body using T1-weighted sequence with and without fat-selective saturation pulses. Selected area of all pixels containing fat ("pure" white) were calculated by outlining with a graph pen and computing the area. The range of the fat area in the plans examined in the $4 \mathrm{AL}, 18 \mathrm{CR}$, and 18
$\mathrm{AL}(n=3$ from each group) rats is expressed in arbitrary three-digit numbers.

\section{Hyperinsulinemic euglycemic clamp}

We have shown previously that this rodent model demonstrates a decrease in insulin responsiveness up to 4 mo of age, after which time insulin responsiveness does not decrease, even with further fat accretion (24). Thus, we predicted that as long as FM was increased in 18 $\mathrm{CR}$ over $4 \mathrm{AL}$, insulin responsiveness would not change in this model. We studied $4 \mathrm{AL}(n=6), 18 \mathrm{AL}(n=5)$, and $18 \mathrm{CR}(n=5)$ rats by using the euglycemic clamp technique $(23,24)$. Briefly, a primed-continuous infusion of insulin $(18 \mathrm{mU} / \mathrm{kg} \cdot \mathrm{min})$ was administered, and a variable infusion of a $25 \%$ glucose solution was started at time 0 and periodically adjusted to clamp the plasma glucose concentration at basal.

All studied rats received a primed-continuous infusion of HPLCpurified [ $\left.{ }^{3} \mathrm{H}-3\right]$-glucose (New England Nuclear) $(15-40 \mu \mathrm{Ci}$ bolus, 0.4 $\mu \mathrm{Ci} / \mathrm{min})$. Plasma samples for determination of ${ }^{3} \mathrm{H}$-glucose specific activity were obtained at 10-min intervals throughout the saline and the insulin infusions. Plasma samples for determination of plasma insulin, lactate, and FFA concentrations were obtained at 30-min intervals before and during the study. The total volume of blood withdrawn was $\sim 4.0 \mathrm{ml} / \mathrm{study}$; to prevent volume depletion and anemia, a solution $(1: 1 \mathrm{vol} / \mathrm{vol})$ of $\sim 4.0 \mathrm{ml}$ of fresh blood (obtained by heart puncture from a littermate of the test animal) and heparinized saline $(10 \mathrm{U} / \mathrm{ml})$ was infused. At the end of the insulin infusion, rats were anesthetized (pentobarbital $60 \mathrm{mg} / \mathrm{kg} \mathrm{BW}$, intravenously), the abdomen was quickly opened, and rectus abdominal muscle and liver were freeze-clamped in situ with aluminum tongs precooled in liquid nitrogen. The time from the injection of the anesthetic until freeze-clamping of the liver was $<45 \mathrm{~s}$. All tissue samples were stored at $-80^{\circ} \mathrm{C}$ for subsequent analysis.

\section{Hepatic-pancreatic clamp studies}

To demonstrate hepatic insulin resistance, endogenous insulin was suppressed while porcine insulin was replaced peripherally (24). After the basal turnover period, $\left[{ }^{3} \mathrm{H}-3\right]$-glucose infusion was continued with somatostatin $(0.8 \mu \mathrm{g} / \mathrm{kg} / \mathrm{min})$ in order to suppress endogenous insulin secretion. Insulin was then infused at variable rates in the first hour in order to determine the rate required to clamp the plasma glucose levels at fasting levels, and maintained at that rate for an additional hour, at which HGP was determined. Plasma sampling, anesthetization of the rats at the end of the infusion period, obtaining muscle and liver freeze-clamped samples were performed as described above.

These study protocols were reviewed and approved by the Animal Care and Use Committee of the Albert Einstein College of Medicine.

\section{Glucose-6-phosphatase (Glc-6-Pase) kinetics}

Tissues were obtained from liver samples freeze-clamped in situ at the end of the in vivo studies. Liver homogenates were prepared in $50 \mathrm{mM}$ Hepes, $100 \mathrm{mM} \mathrm{KCl}, 1 \mathrm{mM}$ EDTA, $5 \mathrm{mM} \mathrm{MgCl}_{2}$, and $2.5 \mathrm{mM}$ dithioerythritol. Homogenates were centrifuged at $100,000 \mathrm{~g}$ for $45 \mathrm{~min}$ to sediment the microsomal fraction (the supernatant was used for the glucokinase assay). The assay was performed is based on the hydrolysis of Pi from glucose-6-phosphate (Glc-6-P) $(26,28)$. The postmicrosomal fraction had no detectable Glc-6-Pase activity. The microsomal fraction was incubated with $0.5,1.0,2.5,5.0$, and $10.0 \mathrm{mM}$ Glc-6-P. The reaction was carried on at $37^{\circ} \mathrm{C}$, and stopped after $20 \mathrm{~min}$ with a solution containing acid molybdate, with $2 / 9$ vol of $10 \%$ SDS and $1 / 9 \mathrm{vol}$ of $10 \%$ ascorbic acid. It was then incubated for $20 \mathrm{~min}$ at $45^{\circ} \mathrm{C}$, and the absorbency read at $820 \mathrm{~nm}$. A standard curve was constructed using different concentrations of Pi. Each assay was repeated three times from different pieces of individual livers, from each study group. 


\section{Hepatic glycogen synthase and phosphorylase activities}

Hepatic glycogen synthase activity was measured based on the incorporation of radioactivity into glycogen from UDP-[U- $\left.{ }^{14} \mathrm{C}\right]$-glucose as described previously $(24,26)$. To approximate the in vivo conditions, synthase activity was measured in the presence of physiologic 0.11 $\mathrm{mmol} /$ liter Glc-6-P. Fractional velocity represent the mean of the activity ratios in the presence of three physiological UDP-glucose (UDPGlu) concentrations $(0.125,0.25$, and $0.5 \mathrm{mM})$. Hepatic glycogen phosphorylase activity was measured based on the measurement of the incorporation of ${ }^{14} \mathrm{C}$ into glycogen from labeled glucose-1-phosphate as described previously $(24,26)$. Glycogen phosphorylase a, the active phosphorylated enzyme, was assayed in the absence of AMP.

\section{Analytical procedures}

Plasma glucose was measured by the glucose oxidase method (Glucose Analyzer II; Beckman Instruments, Inc., Palo Alto, CA) and plasma insulin by radioimmunoassay using rat and porcine insulin standards. Plasma ${ }^{3} \mathrm{H}$-glucose radioactivity was measured in duplicate on the supernatants of $\mathrm{Ba}(\mathrm{OH})_{2}$ and $\mathrm{ZnSO}_{4}$ precipitates of plasma samples after evaporation to dryness to eliminate tritiated water. $\mathrm{He}-$ patic Glc-6-P concentrations were measured spectrophotometrically as described previously $(23,26,27)$. Plasma nonesterified fatty acid concentrations were determined by an enzymatic method with an automated kit according to the manufacturer's specifications (Waco Pure Chemical Industries, Osaka, Japan). Plasma glycerol was measured with an automated kit according to specifications (Sigma Diagnostics, St. Louis, MO).

Terminology. The term total glucose output (TGO) is intended as total in vivo flux through Glc-6-Pase. The term HGP is intended as the net rates of Glc-6-P dephosphorylation to glucose (balance of the in vivo fluxes through glucokinase and Glc-6-Pase). Finally, glucose cycling (GC) is defined as the input of extracellular glucose into the Glc-6-P pool followed by exit of plasma-derived Glc-6-P back into the extracellular pool.

Calculations. After $\left[{ }^{3} \mathrm{H}-3\right]$-glucose infusion, the ratio of specific activities of ${ }^{3} \mathrm{H}$-hepatic UDPGlc and plasma glucose represents the percentage of the hepatic Glc-6-P pool which was derived from plasma glucose. The UDPGlc concentrations and specific activity (SA) were assessed by reverse-phase HPLC as described previously $(26,29)$. Thus, this ratio also measured the percent contribution of plasma glucose to Glc-6-Pase flux (i.e., GC). Since TGO is equal to the sum of HGP plus GC ( $G C={ }^{3} \mathrm{H}$-UDPGlc SA/plasma ${ }^{3} \mathrm{H}$-glucose $S A \times T G O)$, the equation can be resolved to calculate both $\mathrm{GC}$ and TGO: $T G O=H G P /\left(1-{ }^{3} H\right.$-UDPGlc SA/plasma ${ }^{3} H$-glucose $\left.S A\right)$ and $G C={ }^{3} H$-UDPGlc SA/plasma ${ }^{3} \mathrm{H}$-glucose $S A \times T G O$.

While HGP is similar in all groups, the liver is exposed to different insulin levels during the hepatic-pancreatic clamps. To take these insulin levels into account, we previously defined an index for HIS at the basal state, as the rate of basal HGP divided by the mean plasma levels of insulin during the study (24). For the analysis of the relationship between HIS and FM, correlations were analyzed by simple linear regression. In addition, nonlinear regression was performed to fit an exponential decay model of glucose uptake versus parameters of body composition. Also, a piece-wise regression model with an unknown knot point was used. This spline curve model consists of two regression lines joined at an unknown intersection (knot). This unknown knot can be statistically derived by NLIN program in SAS windows, version 6.10 . This model is expressed as: $y=a ̊ a 1 \cdot x+$ $\beta 2 \cdot(x-k) \cdot I k$; where $y$ is HIS, $x$ represents $\mathrm{VF}, k$ is the unknown knot to be estimated from the nonlinear regression procedure, and $I k$ is the indicator variable (which is equal to 1 if $x$ is greater than the knot, and otherwise is 0 ). The model becomes $y=\stackrel{a}{a}+\beta 1 \cdot x$, if $x$ is less than the estimate knot $k$, and $y=(\stackrel{a}{a}-k)+(\beta 1+\beta 2) \cdot x$, if $x$ is greater than or equal to estimated knot $k$. The $P$ values of the two slopes can be derived and will provide the information of how the outcome variable will change after the $x$ variable reached the estimated knot. Comparisons between groups were made using repeated

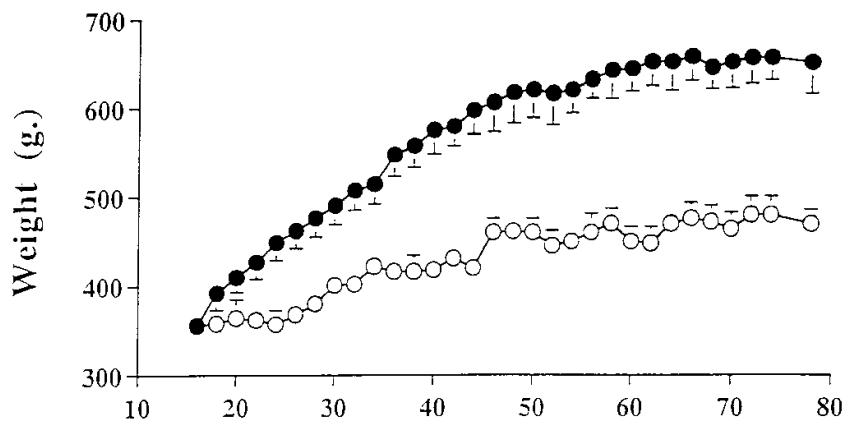

Figure 1. CR effects on BW. BW of Sprague-Dawley rats which were ad libitum fed (filled circles) or calorie restricted (open circles) to $55 \%$ of the consumed $\mathrm{kcal} / \mathrm{d}$ of the AL group beginning at $14-16 \mathrm{wk}$ of age.

measures ANOVA where appropriate. Other values are presented as the mean \pm SEM.

\section{Results}

\section{Weight gain in $C R$ and $A L$ rats}

BW increased significantly until 56 wk of age in AL and until 46 wk of age in CR rats. Thereafter, BW remained stable in both groups and at 18 mo of age the difference between AL and CR averaged $177 \pm 12 \mathrm{~g}$ of $\mathrm{BW}$ (Fig. 1). Rats in the $\mathrm{AL}$ group consumed initially $79 \pm 6 \mathrm{kcal} / \mathrm{d}$ and their food intake remained quite stable throughout the study period. Food intake was decreased in the CR group at $\sim 55 \%(43 \mathrm{kcal} / \mathrm{d})$ of that of $\mathrm{AL}$ rats. At the completion of the study, $18 \mathrm{AL}$ rats gained $\sim 310 \mathrm{~g}$ in $14 \mathrm{mo}$ and weighted twice as much as $4 \mathrm{AL}$. By contrast, $18 \mathrm{CR}$ gained only $\sim 140 \mathrm{~g}$ during the same period of time.

\section{Effect of age and $C R$ on peripheral insulin sensitivity}

Body composition and basal biochemical characteristics of selected rats. FM was dramatically increased in 18 AL but was similar in $4 \mathrm{AL}$ and CR, while VF was significantly lower in 18 CR than it was in $18 \mathrm{AL}$ and $4 \mathrm{AL}$. Plasma basal glucose levels were similar between groups $(7.3 \pm 0.6,7.2 \pm 1.6$, and $7.3 \pm 1.6$ $\mathrm{mM}$ in $4 \mathrm{AL}, 18 \mathrm{AL}$, and $18 \mathrm{CR}$, respectively), while basal plasma insulin levels were lowest in 18 CR $(286 \pm 16,510 \pm 77$,

Table I. Peripheral Insulin Responsiveness

\begin{tabular}{lccc}
\hline & $4 \mathrm{AL}$ & $18 \mathrm{AL}$ & $18 \mathrm{CR}$ \\
\hline & $n=6$ & $n=5$ & $n=5$ \\
BW (g) & $347 \pm 15$ & $633 \pm 63^{*}$ & $468 \pm 44^{\ddagger}$ \\
FM (g) & $51 \pm 6$ & $167 \pm 15^{*}$ & $59 \pm 3$ \\
VF (g) & $13.3 \pm 2.3$ & $43.4 \pm 12.0^{*}$ & $8.3 \pm 1.6^{\ddagger}$ \\
Glucose (mM) & $7.2 \pm 1.2$ & $7.1 \pm 1.4$ & $7.2 \pm 1.2$ \\
Insulin (pM) & $4500 \pm 180$ & $4560 \pm 300$ & $5112 \pm 342$ \\
Rd (mg/kg LBM/min) & $37.5 \pm 2.6$ & $35.6 \pm 5.3$ & $39.4 \pm 2.7$
\end{tabular}

Characteristics of $4 \mathrm{AL}, 18 \mathrm{AL}$, and $18 \mathrm{CR}$ rats. Body composition: $\mathrm{BW}$, LBM, \% FM, and total VF. Plasma glucose and insulin levels during hyperinsulinemic clamp (18 $\mathrm{mU} / \mathrm{kg} / \mathrm{min})$ and glucose uptake (Rd) in terms of LBM. ${ }^{*} P<0.01$ vs. $4 \mathrm{AL},{ }^{\ddagger} P<0.01$ vs. $18 \mathrm{AL}$; data are presented as mean \pm SEM. 
and $179 \pm 34$, in $4 \mathrm{AL}, 18 \mathrm{AL}$, and $18 \mathrm{CR}$, respectively, $P<0.01$ between all groups) (Table I).

Hyperinsulinemic euglycemic clamp studies. During the insulin clamp studies, steady-state plasma glucose and insulin concentrations were similar in all groups. Plasma FFA levels during hyperinsulinemia were suppressed by $\sim 70 \%$, and plasma lactate levels were similarly increased in all groups. When the Rd was expressed per LBM it was similar among all groups. HGP was equally suppressed to $\sim 2 \mathrm{mg} / \mathrm{kg} / \mathrm{min}$ in all groups. Thus, in this model, peripheral insulin responsiveness does not change with aging or with $\mathrm{CR}$ which maintains certain FM, supporting the possibility that the insulin insensitivity which is suggested by basal hyperinsulinemia in this model may reside at the level of the liver (Table I).

\section{Effect of age and CR on HIS}

Body composition and basal biochemical characteristics of selected rats. While BW was increased in $18 \mathrm{AL}$ compared with the other groups, CR only minimally affected LBM, and the decreased accumulation of fat accounted for $\sim 75 \%$ of the diminished weight gain in this group (Table II). Furthermore, while the percent contribution of FM to BW doubled between 4 and 18 mo of age in the AL group, CR completely prevented this increase. Thus, CR blunted the age-associated increase in whole body FM.

Additionally, it is apparent that CR also affected the distribution of body fat. In fact, while whole body FM remained significantly higher in $18 \mathrm{CR}$ than in $4 \mathrm{AL}, \mathrm{VF}$ was decreased in $18 \mathrm{CR}$ below the level measured in 4 AL (Table II). This marked reduction in VF can be visually appreciated in the MRI of a typical $18 \mathrm{AL}$ and $18 \mathrm{CR}$ rat depicted in Fig. 2. Quantitative analysis of all MRIs revealed that the subcutaneous fat (averaged around the scapular and abdominal areas) of 4 AL rats ranged from 120 to 212 (arbitrary units) and it was still increased by $\sim 40 \%$ (to a range of 235-278) in $18 \mathrm{CR}$. Conversely, areas of matching cuts in the planes of epididymal and perinephric fat depots ranged from 472 to 493 in $4 \mathrm{AL}$ and decreased by $\sim 30 \%$ in $18 \mathrm{CR}$ (to $312-349$ ).

Table II displays the basal biochemical parameters in the three experimental groups. Postabsorptive ( 6 of fasting) plasma

Table II. Characteristics of 4AL, 18 AL, and 18 CR Rats

\begin{tabular}{lccc}
\hline & $4 \mathrm{AL}$ & $18 \mathrm{AL}$ & $18 \mathrm{CR}$ \\
\hline & $n=7$ & $n=7$ & $n=6$ \\
BW $(\mathrm{g})$ & $330 \pm 22$ & $643 \pm 31^{*}$ & $471 \pm 20^{* \ddagger}$ \\
LBM (g) & $285 \pm 15$ & $453 \pm 24^{*}$ & $412 \pm 23^{*}$ \\
FM (g) & $45 \pm 6$ & $190 \pm 12^{*}$ & $65 \pm 6^{* \ddagger}$ \\
FM (\%) & $13 \pm 3$ & $26 \pm 3^{*}$ & $13 \pm 4^{\ddagger}$ \\
VF (g) & $12.3 \pm 3.3$ & $35.9 \pm 6.7^{*}$ & $7.8 \pm 0.6^{* \ddagger}$ \\
Glucose (mM) & $7.4 \pm 0.8$ & $7.6 \pm 1.4$ & $7.3 \pm 1.0$ \\
Insulin (pM) & $266 \pm 12$ & $491 \pm 88^{*}$ & $149 \pm 34^{\ddagger}$ \\
FFA (mM) & $1.02 \pm 0.09$ & $1.78 \pm 0.23^{*}$ & $1.21 \pm 0.12^{\ddagger}$ \\
Glycerol (RM) & $110 \pm 12$ & $228 \pm 32^{*}$ & $152 \pm 31^{\ddagger}$ \\
Lactate (mM) & $0.57 \pm 0.06$ & $0.55 \pm 0.02$ & $0.54 \pm 0.04$ \\
& & &
\end{tabular}

Body composition: BW, LBM, FM, epididymal fat pad, and total VF. Biochemical characteristics: fasting plasma glucose, insulin, FFA, glycerol, and lactate. ${ }^{*} P<0.01$ vs. $4 \mathrm{AL},{ }^{\ddagger} P<0.01$ vs. $18 \mathrm{AL}$; data are presented as mean \pm SEM. glucose and lactate concentrations were similar in all groups. However, plasma insulin, FFA, and glycerol levels nearly doubled in $18 \mathrm{AL}$ as compared with $4 \mathrm{AL}$. In $18 \mathrm{CR}$, plasma insulin levels decreased to levels which were significantly below those of 4 AL $(\sim 60 \%)$, while plasma FFA and glycerol levels were nearly normalized (Table II).

HIS. On the day of the study, the fasting plasma glucose concentrations and the basal HGP $(62 \pm 4,64 \pm 5$, and $62 \pm 4$ $\mu \mathrm{mol} / \mathrm{kg} / \mathrm{min}$ ) were similar in $4 \mathrm{AL}, 18 \mathrm{AL}$, and $18 \mathrm{CR}$, respectively. The rate of insulin infusion needed to clamp the plasma glucose at basal levels was $0.75 \pm 0.10 \mathrm{mU} / \mathrm{kg} / \mathrm{min}$ in $4 \mathrm{AL}$, $1.41 \pm 0.13 \mathrm{mU} / \mathrm{kg} / \mathrm{min}$ in $18 \mathrm{AL}$, and $0.51 \pm 0.12 \mathrm{mU} / \mathrm{kg} / \mathrm{min}$ in $18 \mathrm{CR}$ (Fig. 3; $P<0.01$ between all groups). Plasma glucose concentrations were maintained at fasting levels $(7.5 \pm 0.2$, $7.4 \pm 0.4$, and $7.2 \pm 0.3 \mathrm{mM}$ ) throughout the study. HGP was slightly decreased from basal and was $58 \pm 4,56 \pm 6$, and $54 \pm 4$ $\mu \mathrm{mol} / \mathrm{kg} / \mathrm{min}$ in $4 \mathrm{AL}, 18 \mathrm{AL}$, and $18 \mathrm{CR}$, respectively. Plasma FFA levels during insulin infusion were $0.76 \pm 0.04,1.64 \pm 0.02$, and $1.09 \pm 0.06 \mathrm{mM}$ in $4 \mathrm{AL}, 18 \mathrm{AL}$, and $18 \mathrm{CR}$, respectively. Glucagon levels were similar in all groups during the hepaticpancreatic clamp 238 $\pm 34,227 \pm 31$, and $190 \pm 24 \mathrm{pg} / \mathrm{ml}$ in $4 \mathrm{AL}$, $18 \mathrm{AL}$, and $18 \mathrm{CR}$, respectively. The above rates of insulin infusion resulted in a twofold higher plasma insulin levels in 18

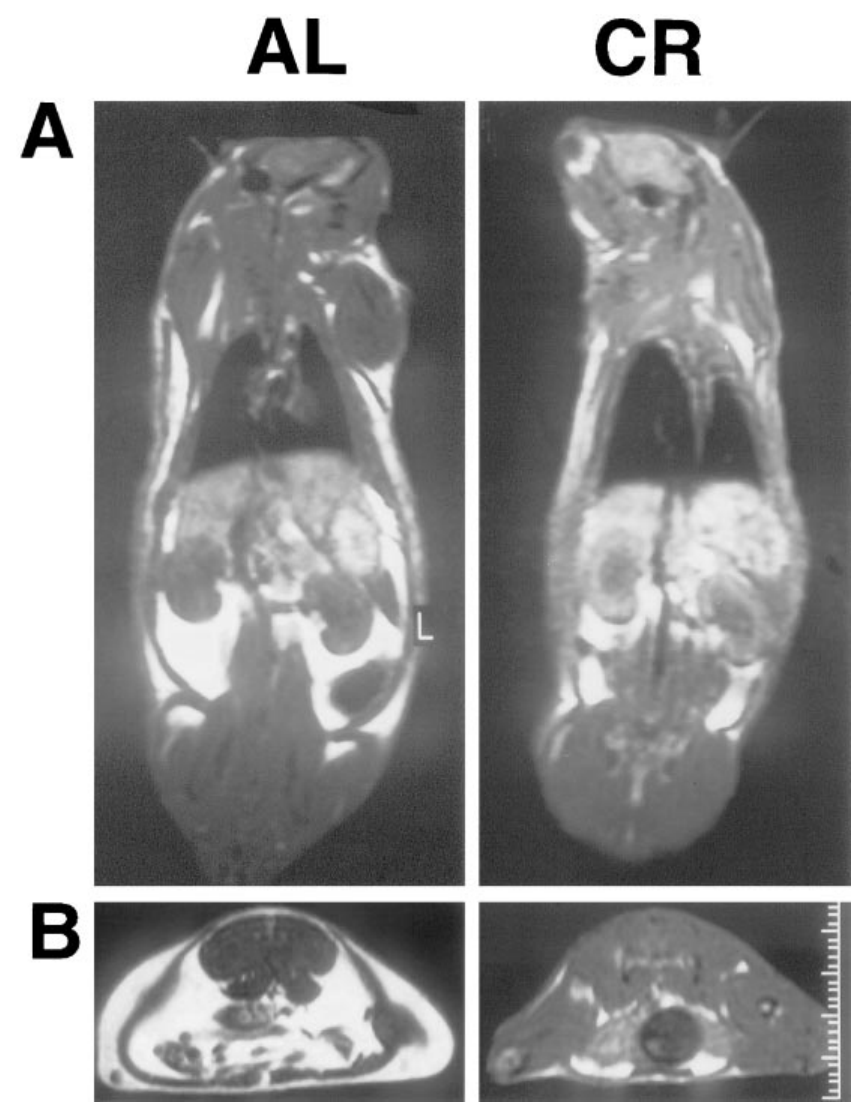

Figure 2. Body composition by MRI. The bright white color depicts fat tissue. $(A)$ Coronal cut in the dorsal plane which demonstrates the kidneys and the surrounding perinephric fat, in AL and CR 18mo-old rats. While the amount of perinephric fat is dramatically decreased by CR, the subcutaneous fat (best seen around the chest) is decreased to a lesser extent. ( $B$ ) Cross-sectional cut above the level of the pelvis in AL and CR rats demonstrates a dramatic decrease in mesenteric fat in CR. 
AL, but significantly lower levels in $18 \mathrm{CR}(197 \pm 33,461 \pm 80$, and $132 \pm 18 \mathrm{pmol} /$ liter in $4 \mathrm{AL}, 18 \mathrm{AL}$, and $18 \mathrm{CR}$, respectively; $P<0.001$ among all groups) (Fig. $4 A$ ). Portal plasma insulin levels obtained at the end of the study did not demonstrate a significant gradient with the systemic plasma insulin levels $(207 \pm 43,486 \pm 91$, and $128 \pm 28 \mathrm{pmol} / \mathrm{liter}$ in $4 \mathrm{AL}, 18$ AL, and $18 \mathrm{CR}$, respectively; $P<0.001$ among all groups). An index of HIS was derived by dividing the rate of HGP by the steady-state plasma insulin concentrations. HIS was decreased by $\sim 50 \%$ in 18 AL compared with 4 AL but it was increased

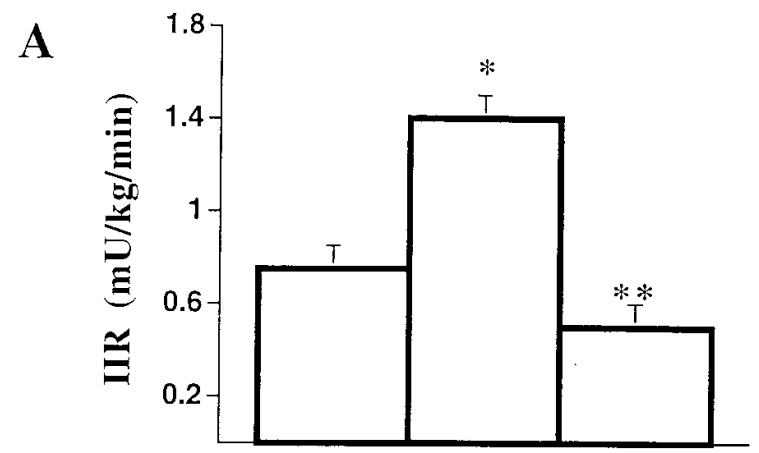

B

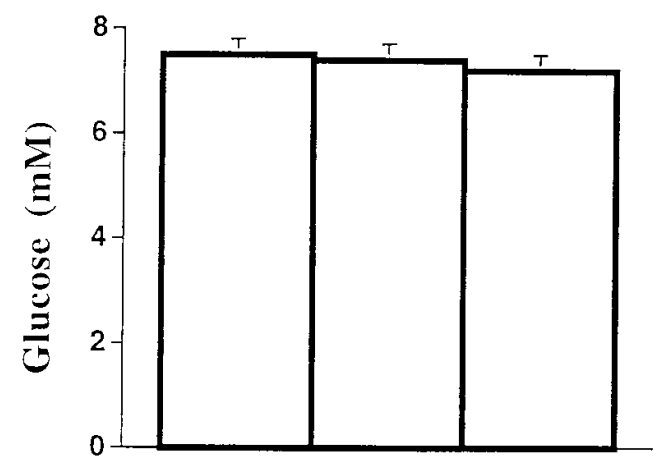

$\mathrm{C}$

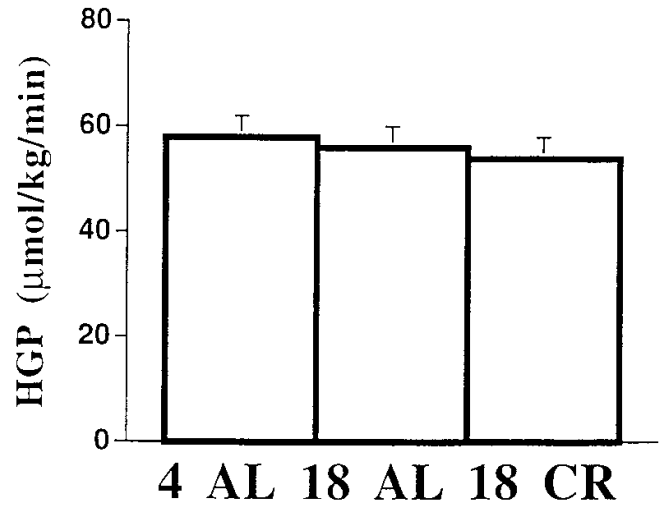

Figure 3. IIR, plasma glucose, and HGP, during the hepatic-pancreatic clamp. Somatostatin $(0.8 \mu \mathrm{g} / \mathrm{kg} / \mathrm{min})$ was infused to decrease endogenous insulin secretion while insulin was infused peripherally at variable rates in the first hour in order to clamp the glucose levels at fasting levels, and maintained at that rate for an additional hour. Studies were performed in $4 \mathrm{AL}, 18 \mathrm{AL}$, and $18 \mathrm{CR}$ rats. $(A)$ IIR required to maintain plasma glucose at basal values in the last $60 \mathrm{~min}$ of the hepatic-pancreatic clamp. ${ }^{*} P<0.001,{ }^{*} P P<0.01$ vs. 4 AL. $(B)$ Plasma glucose levels at the last $60 \mathrm{~min}$ of the hepatic-pancreatic clamp. (C) HGP at the last $60 \mathrm{~min}$ of the hepatic-pancreatic clamp. twofold in $18 \mathrm{CR}[0.277 \pm 0.028,0.143 \pm 0.006$, and $0.461 \pm 0.021$ $(\mu \mathrm{mol} / \mathrm{kg} / \mathrm{min}) /(\mathrm{pmol} / \mathrm{liter})$ in $4 \mathrm{AL}, 18 \mathrm{AL}$, and $18 \mathrm{CR}$, respectively; $P<0.001$ among all groups] (Fig. $4 B$ ).

To confirm the beneficial effect of CR on HIS, an additional group of $18 \mathrm{CR}$ was infused with insulin at the rate (1.4 $\mathrm{mU} / \mathrm{kg} / \mathrm{min}$ ) required to clamp the plasma glucose levels in the 18 AL $(n=4)$. Plasma glucose concentrations were maintained at basal level by glucose infusion and HGP was assessed. HGP was $70 \pm 8$ during the basal period and it was suppressed by $32 \%$ to $48 \pm 1 \mu \mathrm{mol} / \mathrm{kg} / \mathrm{min}(P<0.005)$ during the insulin infusion.

Relationship between hepatic insulin action and VF. Changes in VF were tightly associated with alterations in the rate of insulin infusion (IIR) needed to maintain HGP (Fig. 5). Because the individual points between VF and HIS do not seem to have simple correlation, we searched for the best fit model for this relationship. This was obtained by spline curve analysis consisting of the two regression lines joined in a knot at VF weighing $12.6 \mathrm{~g}\left(P<0.0006 ; R^{2}=0.957 ;\right.$ Fig. 6$)$. When $\mathrm{VF}$ was $<12.6 \mathrm{~g}$, the slope was: HIS $=0.30-0.004 \times$ total $V F,(r=-0.851, P<$ $0.001)$, and when total VF was $>12.6 \mathrm{~g}$ the steep slope was milder $(H I S=0.78-0.042 \times$ total $V F)(r=-0.875, P<0.001)$. HIS was also inversely correlated with VF when analyzed by regression line $(r=-0.751, P<0.001)$ or by exponential decay $(r=0.875, P<0.001)$. When exponential decay is plotted

A

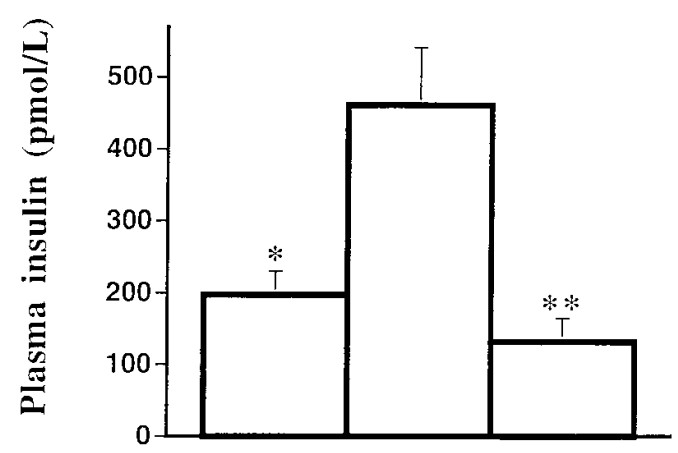

B

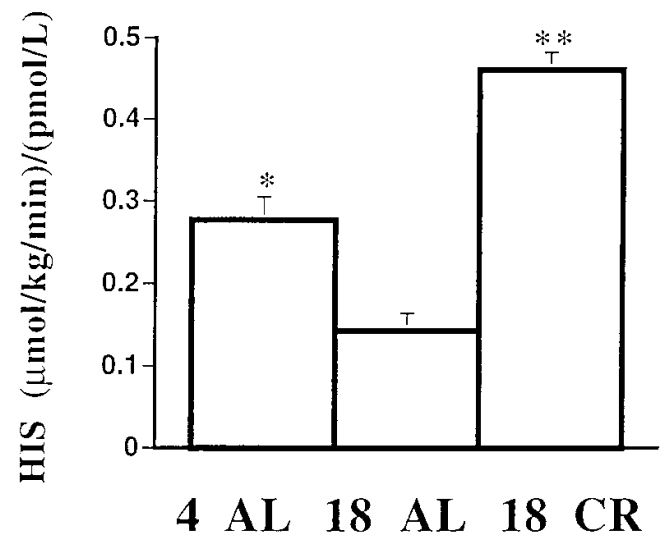

Figure 4. Plasma insulin levels and HIS during the hepatic pancreatic clamp. (A) The plasma insulin levels achieved at the last $60 \mathrm{~min}$ of the hepatic-pancreatic clamp in $4 \mathrm{AL}, 18 \mathrm{AL}$, and $18 \mathrm{CR}$ rats. $* P<0.001$ vs. $18 \mathrm{AL},{ }^{* *} P<0.01$ vs. $4 \mathrm{AL}$. (B) To take basal insulin levels into account while measuring HGP, we defined the index HIS as the rate of HGP divided by the mean plasma levels of insulin during the study. $* P<0.001$ vs. $18 \mathrm{AL}, * * P<0.001$ vs. 4 AL. 


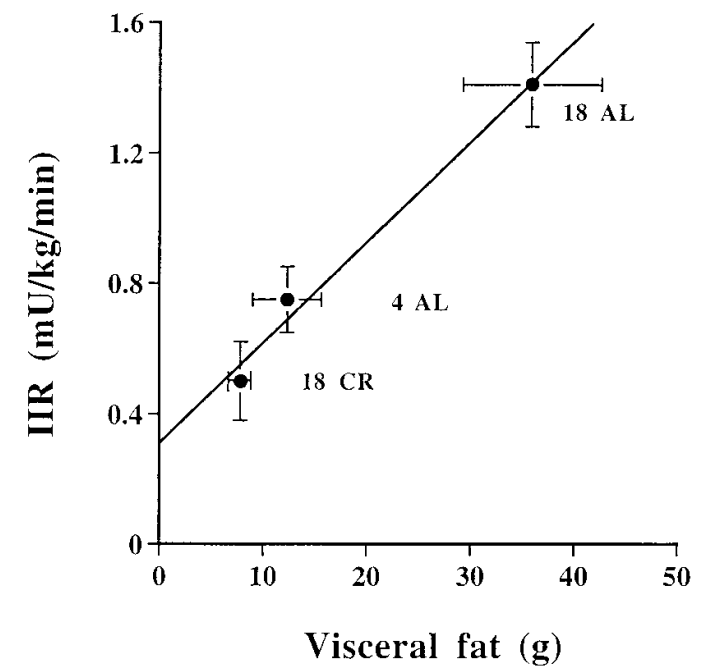

Figure 5. The relationship between IIR and VF. Points presenting the $4 \mathrm{AL}, 18 \mathrm{AL}$, and $18 \mathrm{CR}$ rats.

between HIS and VF, the decay clearly leaves the low VF and high HIS (most of the 18 CR group) away from the curve.

While FM was also correlated with HIS, this correlation was weaker than that shown with VF when calculated either by linear regression $(r=-0.616, P<0.05)$ or by exponential decay $(r=0.765, P<0.005)$. This figure also demonstrates how the decay leaves the low FM and high HIS away from the curve. Spline curve analysis of the relationship between FM

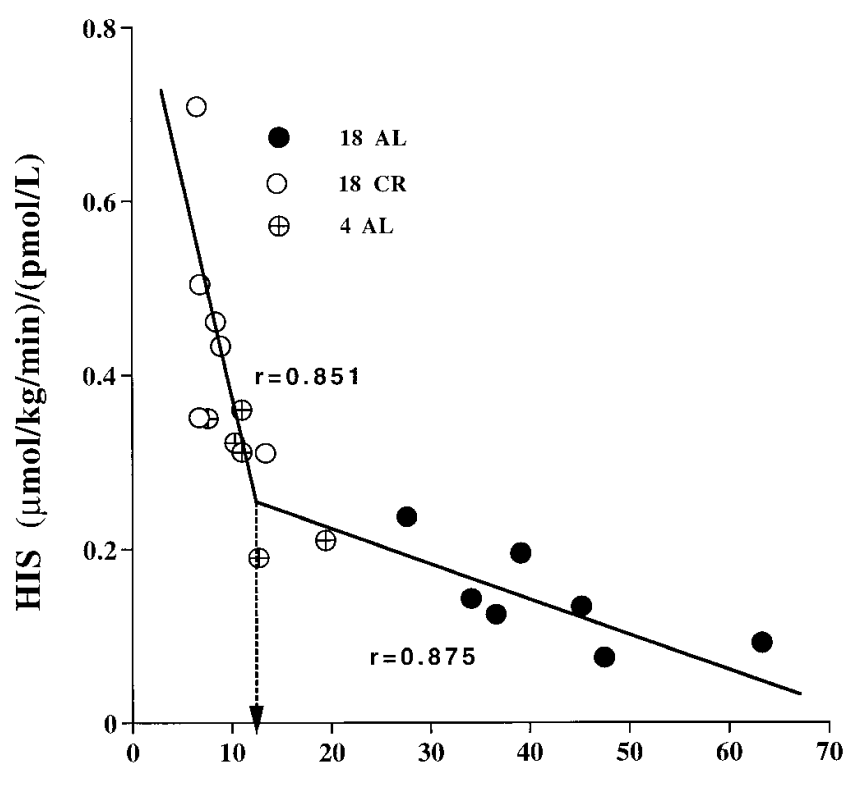

Total visceral fat (g.)

Figure 6. The relationship between HIS and VF. Points presenting the $4 \mathrm{AL}, 18 \mathrm{AL}$, and $18 \mathrm{CR}$ rats. These points best fit the spline curve model which reveals a significant knot at total abdominal fat of $12.6 \mathrm{~g}(P<0.0006)$. Regression lines were analyzed in rats with total abdominal fat greater than or less than $12.6 \mathrm{~g}(P<0.001$ for both lines). and HIS also demonstrated a knot at $\mathrm{FM}=47.2 \mathrm{~g}$; however, this was less significant $\left(P=0.039 ; R^{2}=0.861\right)$ than with VF.

A linear inverse relationship was also demonstrated between plasma FFA concentrations and HIS in $18 \mathrm{AL}$ and 18 $\mathrm{CR}(r=-0.640, P<0.001)$ and between $4 \mathrm{AL}$ and $18 \mathrm{CR}(r=$ $-0.623, P<0.001)$. However, when all groups were combined, this correlation did not achieve statistical significance $(r=$ $0.425, P<0.06$; not shown). This appeared to be due to the presence of higher HIS and plasma FFA levels in $18 \mathrm{CR}$ than in 4 AL.

Refeeding of 18 CR rats. A subgroup $(n=6)$ of 18 CR was fed ad libitum (18 CR refed) for $14 \mathrm{~d}$. Caloric intake promptly increased by $59 \%$ and $\mathrm{BW}$ was increased from the state before refeeding by $6 \pm 1 \%$ to $481 \pm 14 \mathrm{~g}$ (vs. $471 \pm 20 \mathrm{~g}$ of $18 \mathrm{CR}$ ). While LBM was similar to that of $18 \mathrm{CR}$, there was a moderate increase in FM (by $\sim 11 \%$ or $7 \mathrm{~g}$ ) which did not reach statistical significance. However, the increases in total VF, as well as in the epididymal, perinephric, and mesenteric depots were significantly increased by $\sim 60 \%$ or $\sim 5 \mathrm{~g}$. Thus, the increase in VF during short-term refeeding of CR rats accounts for $\sim 70 \%$ of the increase in total FM. To examine the impact of this nutritional manipulation on hepatic insulin action, hepatic-pancreatic clamp studies were also performed in this group of rats. The IIR needed to achieve euglycemia in $18 \mathrm{CR}$ refed and the plasma insulin concentration were $\sim 2.5$-fold higher than those required to maintain the plasma glucose and HGP at basal levels in $18 \mathrm{CR}$, resulting in a substantial decrease $(\sim 50 \%)$ in HIS (Table III).

Effect of age and CR on hepatic glucose fluxes, activity of key enzymes, and substrate levels. The contribution of plasma glucose to the Glc-6-P pool was calculated from the specific activities of UDPglu and plasma glucose (Table IV). While HGP was kept at similar levels by a variable insulin infusion, the total flux through Glc-6-Pase (TGO) was modestly but significantly decreased in 18 AL. Similarly, the rate of GC was decreased by $45 \%$ in 18 AL. Since the in vivo flux through Glc-6-Pase is largely regulated by the activity of this enzyme and by the size of the Glc-6-P pool, we measured these two pa-

Table III. Body Composition and Metabolic Characteristics after Refeeding of 18 CR Rats

\begin{tabular}{lcc}
\hline & $18 \mathrm{CR}$ & $18 \mathrm{CR}$ refed \\
\hline & $n=6$ & $n=6$ \\
LBM $(\mathrm{g})$ & $412 \pm 23$ & $406 \pm 11$ \\
FM $(\mathrm{g})$ & $65 \pm 6$ & $72 \pm 6$ \\
VF $(\mathrm{g})$ & $7.8 \pm 0.6$ & $12.4 \pm 0.7^{*}$ \\
Epididymal fat pad $(\mathrm{g})$ & $3.8 \pm 0.6$ & $5.6 \pm 0.3^{*}$ \\
Mesenteric fat $(\mathrm{g})$ & $2.3 \pm 0.1$ & $3.6 \pm 0.2^{*}$ \\
Perinephric fat $(\mathrm{g})$ & $1.7 \pm 0.5$ & $3.3 \pm 0.4^{*}$ \\
Glucose $(\mathrm{mM})$ & $7.2 \pm 1.2$ & $7.2 \pm 1.7$ \\
Insulin $(\mathrm{pM})$ & $132 \pm 18$ & $324 \pm 29^{*}$ \\
IIR $(\mathrm{mU} / \mathrm{kg} / \mathrm{min})$ & $0.51 \pm 0.12$ & $1.26 \pm 0.15^{*}$ \\
HIS $(\mu \mathrm{mol} / \mathrm{kg} / \mathrm{min}) /(\mathrm{pmol} / \mathrm{liter})$ & $0.461 \pm 0.021$ & $0.233 \pm 0.027^{*}$ \\
& & \\
\hline
\end{tabular}

Body composition: LBM, FM, total VF, epididymal fat pad, mesenteric fat, and perinephric fat. Plasma glucose and insulin levels during the hepatic pancreatic clamp, IIR, and HIS. ${ }^{*} P<0.001$ vs. $18 \mathrm{CR}$; data are presented as mean \pm SEM. 
rameters in liver samples freeze-clamped in situ at the end of the clamp studies. While the $K_{\mathrm{m}}$ for Glc-6-P was similar in the three groups, the Glc-6-Pase $V_{\max }$ was decreased by $\sim 50 \%$ in $18 \mathrm{AL}$ and by $\sim 30 \%$ in $18 \mathrm{CR}$ (Table V). Thus, a decrease in Glc-6-Pase activity was associated with aging independent of caloric intake. However, this decrease in Glc-6-Pase $V_{\max }$ was largely offset by increased concentration of the substrate (Glc6-P). Finally, neither age nor CR altered the levels of hepatic glycogen, nor the activities of glycogen synthase and phosphorylase (Table VI).

\section{Discussion}

Aging is associated with progressive increases in fasting plasma insulin levels and visceral adiposity in humans (1-3, $8-10)$ and in animal models $(23,24)$. Although HGP plays a pivotal role in the regulation of postabsorptive carbohydrate metabolism (30), the interactions between VF and HGP remain poorly defined (31). Here we investigated the relationship between VF and the action of insulin on hepatic glucose fluxes in a well-characterized rodent model of aging $(23,24)$. In particular, we used chronic CR to examine whether prevention of the age-associated increase in VF could reverse hepatic insulin resistance. Several lines of evidence indicate that in this animal model VF is indeed a major determinant of HIS regardless of age. Hepatic insulin action was highly correlated with VF in all experimental groups. In fact, a statistical analysis of the results revealed that up to $96 \%$ of the variance in HIS can be accounted for by variance in visceral adiposity. CR lowered VF below the levels observed in young (4 AL) rats and markedly improved hepatic (but not peripheral) insulin sensitivity. Furthermore, the hepatic sensitivity to insulin was higher in old CR than in young rats despite higher whole body FM in the former. Finally, short-term (14 d) refeeding of old $\mathrm{CR}$ rats rapidly increased $\mathrm{VF}$ and induced marked hepatic insulin resistance. Altogether, these results suggest that the agerelated increase in VF is likely to play a major role in fasting hyperinsulinemia and hepatic insulin resistance in this rodent model of aging. However, it should be pointed out that up to $86 \%$ of the variance in HIS could be accounted for by changes in total FM. Since changes in VF are a component of the changes in total FM and these two variables are therefore

Table IV. Hepatic Glucose Fluxes

\begin{tabular}{lrcc}
\hline & \multicolumn{1}{c}{$4 \mathrm{AL}$} & $18 \mathrm{AL}$ & $18 \mathrm{CR}$ \\
\hline$\left[{ }^{3} \mathrm{H}\right] \mathrm{Glc}(\mathrm{dpm} / \mathrm{nmol})$ & $41.5 \pm 4.3$ & $39.4 \pm 4.2$ & $61.2 \pm 8.3$ \\
{$\left[{ }^{3} \mathrm{H}\right] \mathrm{UDPGlc}(\mathrm{dpm} / \mathrm{nmol})$} & $9.4 \pm 1.1$ & $6.5 \pm 1.7$ & $12.6 \pm 2.2$ \\
Direct $(\%)$ & $22.7 \pm 3.1$ & $16.5 \pm 2.5$ & $20.0 \pm 2.5$ \\
TGO $(\mathrm{mg} / \mathrm{kg} / \mathrm{min})$ & $14.2 \pm 0.4$ & $12.4 \pm 0.4^{*}$ & $13.6 \pm 0.4$ \\
GC $(\mathrm{mg} / \mathrm{kg} / \mathrm{min})$ & $3.6 \pm 0.4$ & $2.0 \pm 0.6^{*}$ & $2.9 \pm 0.3^{*}$
\end{tabular}

After $\left[{ }^{3} \mathrm{H}-3\right]$-glucose infusion, the ratio of specific activities of hepatic $\left[{ }^{3} \mathrm{H}\right]$ UDP glucose and plasma $\left[{ }^{3} \mathrm{H}\right]$-glucose represents the percentage of the hepatic Glc-6-P pool which is derived from plasma glucose. TGO is intended as total in vivo flux through Glc-6-Pase. GC is defined as the input of extracellular glucose into the Glc-6-P pool followed by exit of plasma-derived Glc-6-P back into the extracellular pool (see Methods). $* P<0.01$ vs. $4 \mathrm{AL}$; data are presented as mean \pm SEM.
Table V. Hepatic Glc-6-Pase and Glc-6-P

\begin{tabular}{lccc}
\hline & $4 \mathrm{AL}$ & $18 \mathrm{AL}$ & $18 \mathrm{CR}$ \\
\hline a-Glc-6-Pase $(\mu \mathrm{mol} / \mathrm{g}$ liver/min) & $16.5 \pm 1.1$ & $8.4 \pm 1.7 *$ & $11.6 \pm 2.2^{*}$ \\
b-Glc-6-Pase $(\mu \mathrm{mol} / \mathrm{kg} \mathrm{BW} / \mathrm{min})$ & $650 \pm 47$ & $248 \pm 50^{*}$ & $394 \pm 72^{*}$ \\
Glc-6-P (nmol/g liver) & $325 \pm 53$ & $443 \pm 42 *$ & $518 \pm 70^{*}$
\end{tabular}

The a-Glc-6-Pase $V_{\max }$ is expressed per grams of liver. In addition, the glucose dephosphorylation capacity was estimated for the whole liver and then calculated in terms of glucose contributed per kilogram of BW, to demonstrate the relative capacity of rats of substantially different weights, to provide glucose from the liver (b-Glc-6-Pase). Glc-6-P levels are presented as per gram of liver. ${ }^{*} P<0.01$ vs. $4 \mathrm{AL}$; data are presented as mean \pm SEM.

tightly linked, our data cannot ascertain whether FM exerts effects on hepatic insulin action which are independent of its covariance with VF.

The aging Sprague-Dawley rat demonstrates several of the main metabolic features of human aging (1-6), including progressive increases in FM, VF, plasma insulin, and FFA levels with age $(23,24)$. While the role of age-related increases in adiposity may be exaggerated in this rat model, it allows one to examine the mechanisms by which fat accretion impacts on metabolism with aging. Because this study was undertaken to investigate whether VF plays a pivotal role in the regulation of HIS, we wished to study the experimental animals at a time when their energy consumption and body composition had achieved a stable steady state. Thus, we restricted the caloric intake of young rats in a chronic fashion until they were $18 \mathrm{mo}$ old (Fig. 1). It should be pointed out that a similar degree of $\mathrm{CR}$ failed to alter HIS when implemented for just $8 \mathrm{~d}$ before the study (29). Thus, the restrictions in daily food intake in the week immediately preceding the in vivo studies are not likely to play a major role in our findings. This dietary intervention resulted in less FM but similar LBM in $18 \mathrm{CR}$ than in $18 \mathrm{AL}$. Most important, while $18 \mathrm{CR}$ rats had a greater amount of FM than 4 AL, they had less total VF (Tables I and II). These changes in fat distribution were demonstrated by assessment of the distribution space of water, by postmortem dissection, and by MRI studies. Therefore, this model enabled us to investigate the impact of age-related increases in VF and total FM.

Table VI. Glycogen Levels and the Enzyme Activities of Hepatic Glycogen Synthase (GS) and Glycogen Phosphorylase (GP)

\begin{tabular}{lrcr}
\hline & $4 \mathrm{AL}$ & $18 \mathrm{AL}$ & $18 \mathrm{CR}$ \\
\hline Glycogen ( $\mu \mathrm{mol} / \mathrm{g}$ liver $)$ & $88 \pm 11$ & $79 \pm 12$ & $74 \pm 22$ \\
GS $(\%)$ & $29.4 \pm 2.0$ & $27.8 \pm 1.6$ & $31.6 \pm 4.1$ \\
GP $(\mu \mathrm{mol} / \mathrm{g}$ liver/min) & $15.4 \pm 2.0$ & $15.6 \pm 2.8$ & $10.8 \pm 2.8$ \\
\hline
\end{tabular}

The enzymes' activities were obtained from liver freezed-clamp in situ by spectrophotometric method from $4 \mathrm{AL}, 18 \mathrm{AL}$, and $18 \mathrm{CR}$ rats. The fractional velocity (FV 0.1) for the hepatic glycogen synthase represents the mean of the activity ratios in the presence of three physiologic UDPGlu concentrations $(0.125,0.25$, and $0.5 \mathrm{mM})$ with $0.11 \mathrm{mM}$ Glc-6-P. The hepatic active form (a) of GP is the activity in the absence of AMP. Data are presented as mean \pm SEM. 
As previously reported $(23,24)$, the increase in FM with aging was associated with increases in both plasma insulin and FFA levels.

Evidence suggests that in this animal model peripheral insulin sensitivity is decreased at a relatively young age. Indeed, we could not demonstrate any further decrease in insulin responsiveness after late adulthood when fat tissue reached a certain mass (24). While CR was shown to improve insulin sensitivity in lean rodent models which are relatively more calorie restricted (32), we predicted that as long as FM does not decrease to below the levels seen at 4 mo of age, peripheral insulin responsiveness will not improve. As demonstrated, insulin responsiveness (i.e., insulin sensitivity at maximally stimulating insulin levels) did not change significantly by CR when expressed in terms of LBM. This further supports the notion that increased basal plasma insulin levels reflect the decrease in hepatic rather than the peripheral insulin sensitivity.

The ratio of basal HGP to peripheral plasma insulin levels may reflect the degree of HIS in humans and animals. However, peripheral plasma insulin levels fail to account for the gradient between the portal and peripheral plasma insulin levels, which may change with body composition, fat distribution, or with the development of insulin resistance. The hepaticpancreatic clamp approach, providing exogenous insulin and somatostatin infusions while maintaining a constant plasma glucose concentration, overcomes this problem by erasing the portal/peripheral gradient in plasma insulin levels. On the other hand, this design also results in higher peripheral plasma insulin levels than those during the basal period, as reflected by a modest decrease in both plasma FFA levels and HGP. However, regardless of the study period which is considered, it is clear that the hepatic sensitivity to either endogenous (basal) or exogenous (pancreatic clamp) insulin was significantly decreased with aging. In fact, a doubling of the rate of insulin infusion and of the plasma insulin concentration was necessary to achieve similar rates of HGP as were measured in the young rats. By contrast, $18 \mathrm{CR}$ displayed a marked enhancement in the ability of insulin to suppress HGP even when compared with 4 AL rats (Fig. $4 \mathrm{~B}$ ). Moreover, when a subgroup of 18 $\mathrm{CR}$ rats was infused with rates of insulin infusion similar to those required in the $18 \mathrm{AL}$ rats, their HGP was significantly decreased and maintenance of euglycemia required the infusion of exogenous glucose. Since the present findings demonstrate that CR induces a marked improvement in hepatic insulin action in aging rats, we further analyzed the relationship between HIS and the associated changes in body composition across the various experimental groups. The most striking correlation was found with VF (Fig. 5). It is apparent from our studies that the relationship between HIS and VF is not simply linear (Fig. 6). While an exponential decay curve can be fitted, spline curve analysis best fitted the individual points. It seems that beyond a certain VF mass (12.6 g), additional VF still resulted in further decreased HIS; however, its impact is reduced. Interestingly, saturating effects of FM on peripheral insulin action have been demonstrated in Pima Indians (33) and in our rat model (23), suggesting that once a certain critical level of fat accretion is achieved, further alterations in glucose metabolism are difficult to detect. While the above analysis remains virtually unchanged when the group which was calorie restricted and then refed was excluded, this latter group provides strong additional support for the role of VF in determining HIS. In fact, refeeding of $18 \mathrm{CR}$ rats for $2 \mathrm{wk}$ resulted in a rapid and dramatic increase in VF (by $\sim 5 \mathrm{~g}$ ), accounting for $\sim 70 \%$ of the increase in total FM, and induced severe hepatic insulin resistance.

While the mechanism(s) whereby VF determines insulin sensitivity remain to be delineated, the unique metabolic characteristics of the mesenteric and omental fat depots as concerns the turnover of glycerol, FFA, and lactate are likely to play a role. Indeed, FFA metabolism measured by a variety of methods was shown to be impaired in humans with increased $\mathrm{VF}$ both in vivo (34-36) and in vitro (36-38). Bjorntorp (15) hypothesized that the metabolic importance of VF may be due to the delivery of substrates such as lactate, FFA, and glycerol into the portal system exerting potent and direct effects on the liver. In fact, it is now well established that the plasma FFA concentration is a major modulator of hepatic insulin action $(39,40)$. In keeping with this theory, mesenteric/omental fat is metabolically more important than subcutaneous fat. Thus, sustained differences in the portal concentrations of FFA, glycerol, and lactate between $18 \mathrm{AL}$ and $18 \mathrm{CR}$ reflecting changes in lipid turnover in mesenteric/omental tissue could play a role in the regulation of HIS. Alternative mechanism(s) responsible for the differential effects of visceral and subcutaneous fat depots on glucose metabolism remain to be explored and are the object of intense investigation in several laboratories.

A significant decrease in Glc-6-Pase $V_{\max }$ was shown in both $18 \mathrm{AL}$ and $18 \mathrm{CR}$ rats as compared with young controls (4 AL). While it is possible that aging is associated with adaptive changes in the activity of Glc-6-Pase and in the hepatic levels of Glc-6-P which are independent of circulating substrate and insulin levels, the latter variables should be taken into consideration in interpreting these findings. While HGP was maintained at similar rates in all experimental groups by means of variable rates of insulin infusion, the flux through Glc-6-Pase, estimated in vivo as the rates of TGO and GC, was decreased in 18 AL compared with 4 AL rats. This occurred despite a significant elevation in the hepatic concentration of Glc-6-P. Altogether these data suggest that an increased rate of Glc-6-P formation via gluconeogenesis and/or glycogenolysis rather than increased efficiency of its dephosphorylation to glucose is likely to represent the cause for the diminished sensitivity to insulin in this aging model. In fact, it is reasonable to believe that the chronic portal hyperinsulinemia in 18 AL contributed to the decreased level of gene expression and activity of liver Glc-6-Pase (28). Conversely, even in the presence of hyperinsulinemia, the effect of decreased Glc-6-Pase activity on TGO was offset by a marked increase in Glc-6-P concentration. $18 \mathrm{CR}$ also displayed more modest decreases in TGO, GC, and Glc-6-Pase activity as compared with young rats. Importantly, this occurred in the face of much lower plasma insulin levels, probably reflecting the marked increase in the hepatic sensitivity to insulin. Furthermore, since increased hepatic availability of glucose or FFA can increase the gene expression of Glc-6-Pase independent of insulin $(41,42)$, reductions in the glucose and FFA levels in CR animals after the meal may also contribute to the lower Glc-6-Pase activity in $18 \mathrm{CR}$ rats. Regardless of the molecular mechanism, it is clear that a marked inhibition of the in vivo activity of Glc-6-Pase can be demonstrated in calorie-restricted old rats despite low portal insulin concentrations. In fact, when HGP was equalized in all experimental groups by altering the rates of insulin infusion, the 18 CR group was able to maintain the in vivo flux through Glc-6Pase (TGO) at a level similar to that observed in young rats, 
despite much higher levels of Glc-6-P. Taken together these results indicated that the improvement in HIS with CR is due to a marked decrease in the rate of Glc-6-P dephosphorylation to glucose.

Our results indicate that postabsorptive hyperinsulinemia in aging is likely due to a marked decrease in the ability of insulin to inhibit HGP. They also support the notion that FM in general and the marked age-dependent increase in VF in particular play a pivotal role in this alteration of hepatic carbohydrate metabolism in this animal model of aging. Thus, we propose that specific interventions designed to reduce VF in aging might greatly improve hepatic insulin action. Further studies will be necessary to identify the specific hormonal and/or metabolic signals by which VF regulates hepatic glucose fluxes in the hope to ultimately devise alternative therapeutic interventions.

\section{Acknowledgments}

The authors thank Meizhu Hu and Rong Liu for their excellent technical assistance.

This work was supported by grants from the National Institutes of Health (R01-DK 45024 and ROI-DK 48321), the American Diabetes Association, and by the Core Laboratories of the Albert Einstein Diabetes Research and Training Center (DK 20541). Dr. Barzilai is a recipient of the Paul Beeson Physician Faculty Scholar in Aging Award, and is supported by grants from the National Institutes of Health (KO8-AG00639, R29-AG15003). Dr. Rossetti is the recipient of a Career Scientist Award from the Irma T. Hirschl Trust.

\section{References}

1. Reaven, G.M., and E.P. Reaven. 1985. Age, glucose intolerance, and non-insulin dependent diabetes mellitus. J. Am. Geriatr. Soc. 33:286-290.

2. Davidson, M.B. 1979. The effect of aging on carbohydrate metabolism: a review of the English literature and a practical approach to the diagnosis of diabetes mellitus in the elderly. Metabolism. 28:688-705.

3. Fraze, E., M. Chlou, Y. Chen, and G.M. Reaven. 1987. Age related changes in postprandial plasma glucose, insulin, and FFA concentrations in non-diabetic individuals. J. Am. Geriatr. Soc. 35:224-228.

4. Reaven, G.M. 1988. Role of insulin resistance in human disease (Banting lecture). Diabetes. 37:1595-1607.

5. Kuczmarski, R.J., K.M. Flegal, S.M. Campbell, and C.L. Johnson. 1994. Increasing prevalence of overweight among US adults. The National Health and Nutrition Examination Surveys, 1960 to 1991 (NHANES III). J. Am. Med. Assoc. 272:238-239.

6. Prager, R., P. Wallace, and J.M. Olefsky. 1986. In vivo kinetics of insulin action on peripheral glucose disposal and hepatic glucose output in normal and obese subjects. J. Clin. Invest. 78:472-481.

7. Ferrannini, E., S. Vichi, H. Beck-Nielsen, M. Laakso, G. Paolisso, and U. Smith, European Group for the Study of Insulin Resistance (EGIR). 1996. Insulin action and age. Diabetes. 45:947-953.

8. Shimokata, H., J.D. Tobin, D.C. Muller, D. Elahi, P.J. Coon, and R. Andres. 1989. Studies in the distribution of body fat. I. Effects of age, sex, and obesity. J. Gerontol. 44:M66-M73.

9. Enzi, G., M. Gasparo, P.R. Biondetti, D. Fiore, M. Semisa, and F. Zurlo. 1986. Subcutaneous and visceral fat distribution according to sex, age, and overweight, evaluated by computed tomography. Am. J. Clin. Nutr. 44:737-746.

10. Borkan, G.A., D.E. Hults, S.G. Gerzof, A.H. Robbins, and C.K. Silbert. 1983. Age changes in body composition revealed by computed tomography. $J$. Gerontol. 38:673-677.

11. Peiris, A.N., M.F. Struve, R.A. Mueller, M.B. Lee, and A.H. Kissebah. 1988. Glucose metabolism in obesity: influence of body fat distribution. J. Clin. Endocrinol. Metab. 67:760-767.

12. Colberg, S.R., J.A. Simoneau, F.L. Thaete, and D.E. Kelley. 1995. Skeletal muscle utilization of free fatty acids in women with visceral obesity. J. Clin. Invest. 95:1846-1853.

13. Carey, D.G., A.B. Jenkins, L.V. Campbell, J. Freund, and D.J. Chisholm. 1996. Abdominal fat and insulin resistance in normal and overweight women: direct measurements reveal a strong relationship in subjects at both low and high risk of NIDDM. Diabetes. 45:633-638.

14. Coon, P.J., E.M. Rogus, D. Drinkwater, D.C. Muller, and A.P. Goldberg. 1992. Role of body fat distribution in the decline in insulin sensitivity and glucose tolerance with age. J. Clin. Endocrinol. Metab. 75:1125-1132.

15. Bjorntorp, P. 1990. "Portal" adipose tissue as a generator of risk factors for cardiovascular disease and diabetes. Arteriosclerosis. 10:493-496.

16. Williamson, J., R.A. Kreisberg, and P.W. Pelts. 1966. Mechanisms for the stimulation of gluconeogenesis by fatty acids in perfused rat liver. Proc. Natl. Acad. Sci. USA. 56:247-254.

17. Barzilai, N., J. Stessman, P. Cohen, G. Morali, D. Barzilai, and E. Karnieli. 1989. Glucoregulatory hormone influence on hepatic glucose production in the elderly. Age. 12:13-17.

18. DeFronzo, R.A. 1979. Glucose intolerance and aging: evidence for tissue insensitivity to insulin. Diabetes. 28:1095-1101.

19. Gumbiner, B., A.W. Thorburn, T.M. Difzler, F. Bulacan, and R.R. Henry. 1992. Role of impaired intracellular glucose metabolism in the insulin resistance of aging. Metabolism. 41:1115-1121.

20. Jackson, R.A., M.I. Hawa, R.D. Roshania, B.M. Sim, L. DiSilvio, and J.B. Jaspan. 1988. Influence of aging, on hepatic and peripheral glucose metabolism in human. Diabetes. 37:119-129.

21. Fink, R.I., O.G. Kolterman, J. Griffin, and J.M. Olefsky. 1983. Mechanisms of insulin resistance in aging. J. Clin. Invest. 71:1523-1535.

22. O'Shaughnessy, I.M., T.J. Myers, K. Stepniakowski, P. Nazzaro, T.M. Kelly, R.G. Hoffmann, B.M. Egan, and A.H. Kissebah. 1995. Glucose metabolism in abdominally obese hypertensive and normotensive subjects. Hypertension. 26:186-192.

23. Barzilai, N., and L. Rossetti. 1995. The relationship between changes in body composition and insulin responsiveness in models of aging rats. Am. $J$. Physiol. 269:E591-E597.

24. Barzilai, N., and L. Rossetti. 1996. Age-related changes in body composition are associated with hepatic insulin resistance in conscious rats. Am. J. Physiol. 270:E930-E936.

25. Rossetti, L., D. Smith, G.I. Shulman, D. Papachristou, and R.A. DeFronzo. 1987. Correction of hyperglycemia with phlorozin normalizes tissue sensitivity to insulin in diabetic rats. J. Clin. Invest. 79:1510-1515.

26. Rossetti, L., A. Giaccari, N. Barzilai, K. Howard, G. Sebel, and M. Hu. 1993. Mechanism by which hyperglycemia inhibits hepatic glucose production in conscious rats. Implications for the pathophysiology of fasting hyperglycemia in diabetes. J. Clin. Invest. 92:1126-1134.

27. Wolfe, R.R. 1984. Radioisotopes and Stable Isotopes: Mass Spectrometry Methods. Alan R. Liss, Inc., New York.

28. Barzilai, N., and L. Rossetti. 1993. Role of glucokinase and glucose-6phosphatase in the acute and chronic regulation of hepatic glucose fluxes by insulin. J. Biol. Chem. 268:25019-25025.

29. Barzilai, N., J. Wang, D. Massilon, P. Vuguin, M. Hawkins, and L. Rossetti. 1997. Leptin selectively decreases visceral adiposity and enhances insulin action. J. Clin Invest. 100:3105-3110.

30. DeFronzo, R.A. 1988. The triumvirate: B-cell, muscle, liver. A collusion responsible for NIDDM. Diabetes. 37:667-687.

31. Kissebah, A.H. 1996. Intra-abdominal fat: is it a major factor in developing diabetes and coronary artery disease? Diabetes Res. Clin. Pract. 30(Suppl.): $25-30$

32. Ivy, J.L., J.C. Young, B.W. Craig, W.M. Kohrt, and J.O. Holloszy. 1991. Ageing, exercise and food restriction: effects on skeletal muscle glucose uptake. Mech. Ageing Devel. 61:123-133.

33. Bogardus, C., S. Lillia, D.M. Mott, C. Hollenbeck, and G. Reaven. 1985. Relationship between degree of obesity and in vivo insulin action in man. Am. J. Physiol. 248:E286-E291.

34. Jensen, M.D., M.W. Haymond, R.A. Rizza, P.E. Cryer, and J.M. Miles. 1989. Influence of body fat distribution on free fatty acid metabolism in obesity. J. Clin. Invest. 83:1168-1173.

35. Marin, P., B. Andersson, M. Ottosson, L. Olbe, B. Chowdhury, H. Kvist, G. Holm, L. Sjostrom, and P. Bjorntorp. 1992. The morphology and metabolism of intraabdominal adipose tissue in men. Metabolism. 41:1242-1248.

36. Nicklas, B.J., A.P. Goldberg, L.B. Bunyard, and E.T. Poehlman. 1995 Visceral adiposity is associated with increased lipid oxidation in obese. Am. J. Clin. Nutr. 62:918-922.

37. Busetto, L., M. Digito, P. Dalla Monta, R. Carraro, and G. Enzi. 1993. Omental and epigastric adipose tissue lipolytic activity in human obesity. Effect of abdominal fat distribution and relationship with hyperinsulinemia. Horm. Metabol. Res. 25:365-371.

38. Feinstein, R., H. Kanety, M.S. Papa, B. Lunenfeld, and A. Karasic. 1993. Tumor necrosis factor-alpha suppresses insulin-induced tyrosine phosphorylation of insulin receptor and its substrates. J. Biol. Chem. 268:26055-26057.

39. Boden, G., X. Chen, J. Ruiz, J.V. White, and L. Rossetti. 1994. Mechanisms of fatty acids induced inhibition of glucose uptake. J. Clin. Invest. 93: 2438-2446.

40. Rebrin, K., G.M. Steil, S.D. Mittelman, and R.N. Bergman. 1996. Causal linkage between insulin suppression of lipolysis and suppression of liver glucose output in dogs. J. Clin. Invest. 98:741-749.

41. Massillon, D., N. Barzilai, W. Chen, and L. Rossetti. 1996. Glucose regulates in vivo glucose-6-phosphatase gene expression in the liver of diabetics rats. J. Biol. Chem. 1271:9871-9874.

42. Hawkins, M., N. Barzilai, R. Liu, W. Chen, and L. Rossetti. 1997. Role of the glucosamine pathway in fat-induced insulin resistance. J. Clin. Invest. 99: 2173-2182. 